\title{
EMBRIOLOGÍA de ERYTHROXYLUM HAVANENSE JACQ.
}

\section{(ERYTHROXYLACEAE)}

\author{
Sonia Vázquez-Santana ${ }^{1}$, César A. Domínguez ${ }^{2}$ Y Judith Márquez-Guzmán ${ }^{1}$ \\ 'Laboratorio de Citología, Facultad de Ciencias, Universidad Nacional Autónoma de México, \\ Apartado postal 70-356, Coyoacán, 04510 México, D. F., México. \\ ${ }^{2}$ Instituto de Ecología, Universidad Nacional Autónoma de México, Apartado postal 70-275, Coyoacán, \\ 04510 México, D. F., México.
}

\begin{abstract}
Resumen. Se estudió el desarrollo de las estructuras reproductoras de los morfos pin y thrum de Erythroxylum havanense. La pared de la antera joven presenta una epidermis, un endotecio, una capa media bi- o triestratificada y un tapete secretor binucleado. La pared de antera madura sólo presenta una epidermis y un endotecio. Las tétradas de microsporas son tetrahédricas o isobilaterales. Los granos de polen son tricolporados, bicelulares y con reservas de almidón. Se observaron diferencias en la escultura de la exina entre el polen thrum y pin, siendo verrugada en el morfo thrum y reticulada en el morfo pin. El óvulo es sésil, pendulado, anátropo, bitégmico y crasinucelado. El saco embrionario es heptacelular. Se diferencia un endotelio. El desarrollo del endospermo es nuclear y la parte basal de la nucela persiste durante el desarrollo temprano del endospermo. Ambos tegumentos forman la cubierta seminal.

Palabras clave: Erythroxylum havanense, embriología, morfo pin, morfo thrum, dimorfismo de polen.

Abstract. We studied the development of reproductive structures in pin and thrum morphs of Erythroxylum havanense. The young anther wall consists of an epidermis, endothecium, 1-3 middle layers and a binucleate secretory tapetum. The mature anther wall has only two layers: epidermis and endothecium. Microspore tetrads are tetrahedral or isobilateral. Mature pollen grains are tricolporate, bicellular and contain starch grains. Exine sculpturing is verrugate in thrum pollen and reticulate in pin pollen. The ovule is sessile, pendulous, anatropous, bitegmic and crassinucellate. The embryo sac is heptacellular. An endothelium is differentiated. The endosperm development is nuclear, and the basal part of the nucellus persists during early endosperm development. Both integuments form the seed coat.
\end{abstract}

Keywords: Erythroxylum havanense, embryology, pin morph, thrum morph, pollen dimorphism.

$\mathbf{L}$ a familia Erythroxylaceae tiene una distribución pantropical y consta de cuatro géneros: Aneulophus, Nectaropetalum, Pinacopodium y Erythroxylum. Este último es el mayor de todos, constituido por 200 especies, que corresponden a más del $95 \%$ de las que integran la familia (Cronquist, 1981). A este género pertenecen $E$. coca y E. novogranatense, plantas de gran interés etnobotánico ya que de ellas se extrae la cocaína (Hegnauer, 1966, citado en Boesewinkel y Geenen, 1980). En México el género está representado por siete especies (Standley, 1923), entre las que se encuentra E. havanense Jacq., que es un arbusto perenne, caducifolio, de floración anual, masiva y sincrónica (Domínguez, 1990; Domínguez y Dirzo, 1995), que puede encontrarse tanto en bosques tropicales caducifolios, subcaducifolios y perennifolios. Muchas de las especies de este género son heterostílicas (Ganders, 1979b).

Con respecto al desarrollo de las estructuras reproductoras en la familia Erythroxylaceae, las investigaciones realizadas son escasas. Los géneros Aneulophus, Nectaropetalum y Pinacopodium han sido escasamente estudiados y para el género Erythroxylum la mayoría de los trabajos se han centrado sobre $E$. coca y $E$. novogranatense (Boesewinkel y Geenen, 1980). Muy pocas investigaciones se conocen sobre otras especies (Narayana, 1960, 1964, 1970; Berry et al., 1991). Estos trabajos constituyen investigaciones parciales, ya que en ninguno de ellos se aborda el estudio completo del desarrollo. 


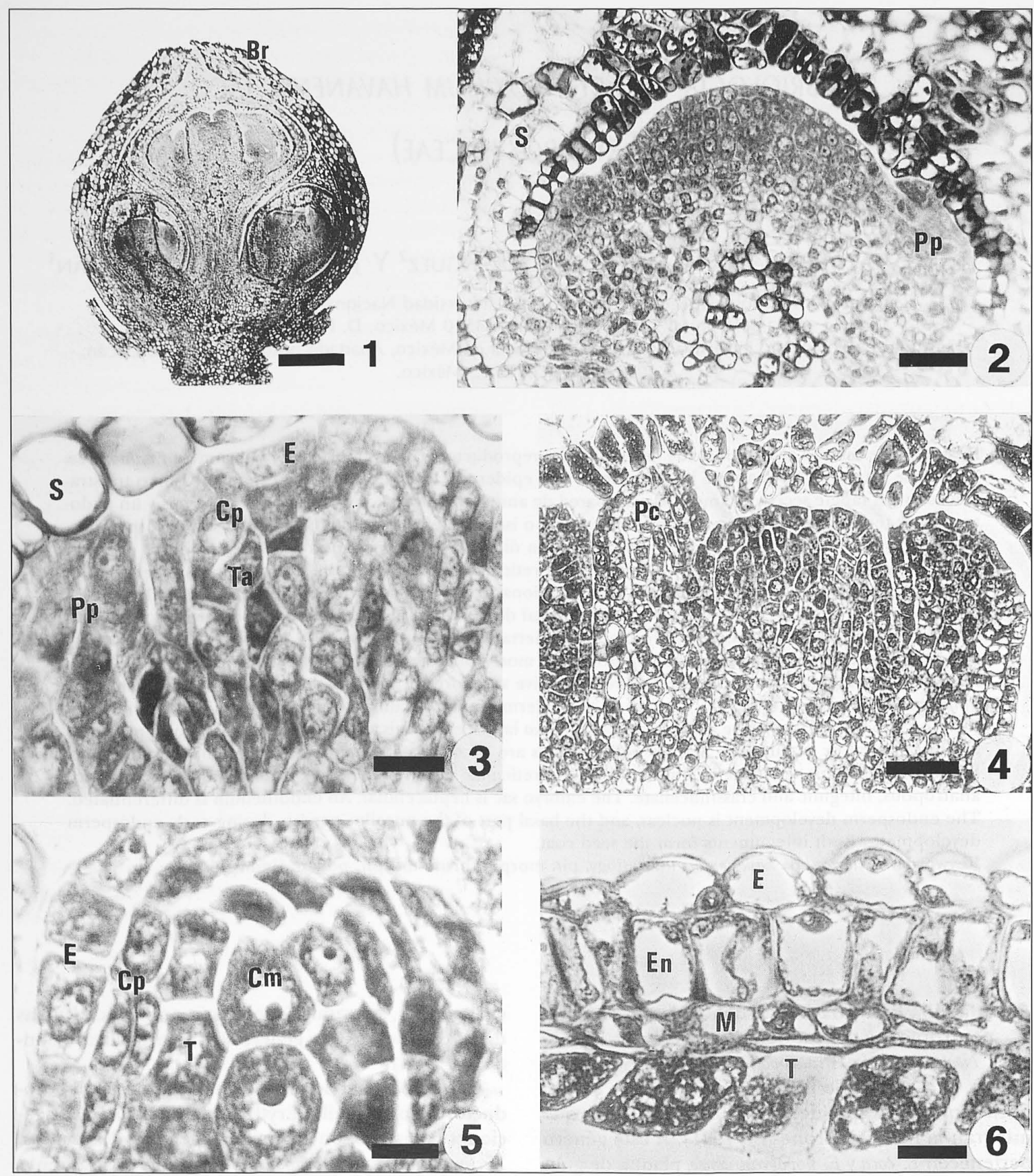

Figuras 1-6. Figura 1. Conjunto de botones florales cubiertos por muchas brácteas, escala $=53.3 \mu \mathrm{m}$. Figura 2. Botón floral mostrando los primordios de pétalos $(\mathrm{Pp})$, escala $=24 \mu \mathrm{m}$. Figura 3. Corte longitudinal de botón floral. Primordios de pétalos (Pp) y estambres. Observe las divisiones periclinales del tejido arquesporial, escala $=8.1 \mu \mathrm{m}$. Figura 4. Primordios carpelares $(\mathrm{Pc})$, escala $=21.1 \mu \mathrm{m}$. Figura 5. Corte transversal de antera. Desarrollo de la pared de antera tipo dicotiledóneo y células madres de las microsporas $(\mathrm{Cm})$, escala $=5.2 \mu \mathrm{m}$. Figura 6 . Corte transversal. Pared de antera joven, escala $=12.1 \mu \mathrm{m}$. (Br, bráctea; $\mathrm{Cm}$, célula madre de la microspora; Cp, capa parietal; E, epidermis; En, endotecio; M, capa media; Pc, primordio carpelar; Pp, primordio de pétalo; S, sépalo; T, tapete; Ta, tejido arquesporial). 
En México, E. havanense se ha estudiado ampliamente y muchos de los aspectos ecológicos de su biología reproductora se conocen en detalle (Domínguez, 1990; Gryj, 1990; Ávila, 1991; Domínguez y Dirzo, 1994, 1995). Las flores son hermafroditas. La mitad de la población presenta flores pin (estilos largos y estambres cortos) y la otra mitad flores thrum (estilos cortos y estambres largos). Sólo las cruzas legítimas, polinizaciones de anteras de un morfo que llegan a estigmas que se encuentran a la misma altura en el morfo contrario, producen semillas (Domínguez, 1990; Ávila, 1991; Domínguez y Dirzo, 1995).

Actualmente, hemos adoptado el sistema reproductor de E. havanense como un modelo para estudiar la evolución de los sistemas reproductores en general y de la heterostilia en particular (Domínguez, 1990; Ávila, 1991).

El propósito de este trabajo fue estudiar comparativamente el desarrollo de las estructuras reproductoras en los morfos pin y thrum de E. havanense desde botón floral hasta la semilla madura.

\section{Materiales y métodos}

El material biológico de $E$. havanense utilizado en este estudio se recolectó durante 1993 y 1994 en la Estación de Biología Chamela (Estado de Jalisco), perteneciente al Instituto de Biología de la Universidad Nacional Autónoma de México. La vegetación predominante de la región es un Bosque Tropical Caducifolio (Rzedowski, 1978).

La recolección se realizó seleccionando al azar 45 individuos. Se incluyeron 24 plantas del morfo pin y 21 plantas del morfo thrum. Se establecieron 30 etapas de desarrollo. Las primeras 5 etapas corresponden al desarrollo de los botones florales, desde primordios, hasta que se desarrollan las anteras y óvulos y al caerse el follaje entran en latencia. Estas 5 etapas se recolectaron aproximadamente de septiembre a diciembre cada 21 días. Las 25 etapas restantes corresponden a botones que pierden la latencia a la siguiente temporada de lluvias y reanudan su crecimiento, se presenta la antesis, la fecundación y el desarrollo de las semillas. Estas etapas se recolectaron desde el inicio de la temporada de lluvias, diariamente hasta la dispersión de los frutos, entre los meses de julio y agosto. El total de muestras procesadas fue aproximadamente de 220 .

En el mismo sitio de recolecta se fijaron en FAA (formaldehido $5 \%$, ácido acético $5 \%$, etanol $63 \%$ y agua destilada $27 \%$ ) o en glutaraldehido $5 \%+$ paraformaldehido $4 \%$ en amortiguador de s-colidina 0.1 $\mathrm{M}, \mathrm{pH}$ 7.2. Posterior a su traslado al laboratorio, el material fijado se lavó en agua o en amortiguador de colidina, dependiendo del fijador utilizado, se deshidrató en etanoles graduales y se incluyó en: A) Paraplast, de acuerdo a la técnica de Johansen (1940) para parafina, o en B) JB-4 (Valley, 1976). Del material incluido en Paraplast se obtuvieron cortes de 8 $\mu \mathrm{m}$ de grosor y se tiñeron con safranina-verde fijo con metilcelosolve; mientras que del material incluido en JB-4, se obtuvieron cortes de 1-2 $\mu \mathrm{m}$ de grosor y se tiñeron con azul de toluidina. También se procesó material para su observación al microscopio electrónico de barrido. Las muestras de polen para microscopía de luz se obtuvieron de botones florales poco antes de la antesis, se deshidrataron y se acetolizaron siguiendo la técnica de Erdtman (1943), previo tratamiento con $\mathrm{KOH}$ al $10 \%$ y los granos de polen se montaron en gelatina glicerinada. Las medidas se hicieron en 20 granos de polen tomados al azar de diversos individuos para cada uno de los morfos. Se aplicó una prueba de $t$ para analizar los resultados.

\section{Resultados}

Los botones florales se desarrollan durante la temporada de lluvias (julio-diciembre), que es cuando $E$. havanense forma el follaje. Al término de esta temporada, se caen las hojas y los botones florales entran en latencia hasta las siguientes lluvias, cuando se produce la reactivación del crecimiento y floración. Los botones florales pequeños se rodean por muchas brácteas que contienen taninos y cristales poligonales (figura 1). Lo que se diferencia primero es el cáliz y desde etapas tempranas del desarrollo se observan algunas células con taninos y las células epidérmicas de ambas superficies tienen prolongaciones digitiformes de aspecto secretor. El segundo verticilo en diferenciarse es la corola (figura 2). Posteriormente los estambres también se elevan del receptáculo como promontorios que comienzan a ensancharse radialmente en su parte apical para formar las anteras (figura 3). Los primordios de los carpelos son los últimos en surgir de la parte central del meristemo (figura 4).

\section{Desarrollo de la antera}

En cada primordio de antera se observa una protodermis que rodea el arquesporio, el cual por divisiones periclinales origina dos tejidos: el más interno se especializa como tejido esporógeno y el más externo (en posición subepidérmica) como tejido parietal primario (figura 3), del cual se formará la pared de la antera, cuyo desarrollo es del tipo dicotiledóneo (figura 5). La pared de una antera joven consta de la epidermis y el endotecio uniestratificados, una capa media bi o triestratificada y un tapete secretor con células binucleadas (figura 6). 


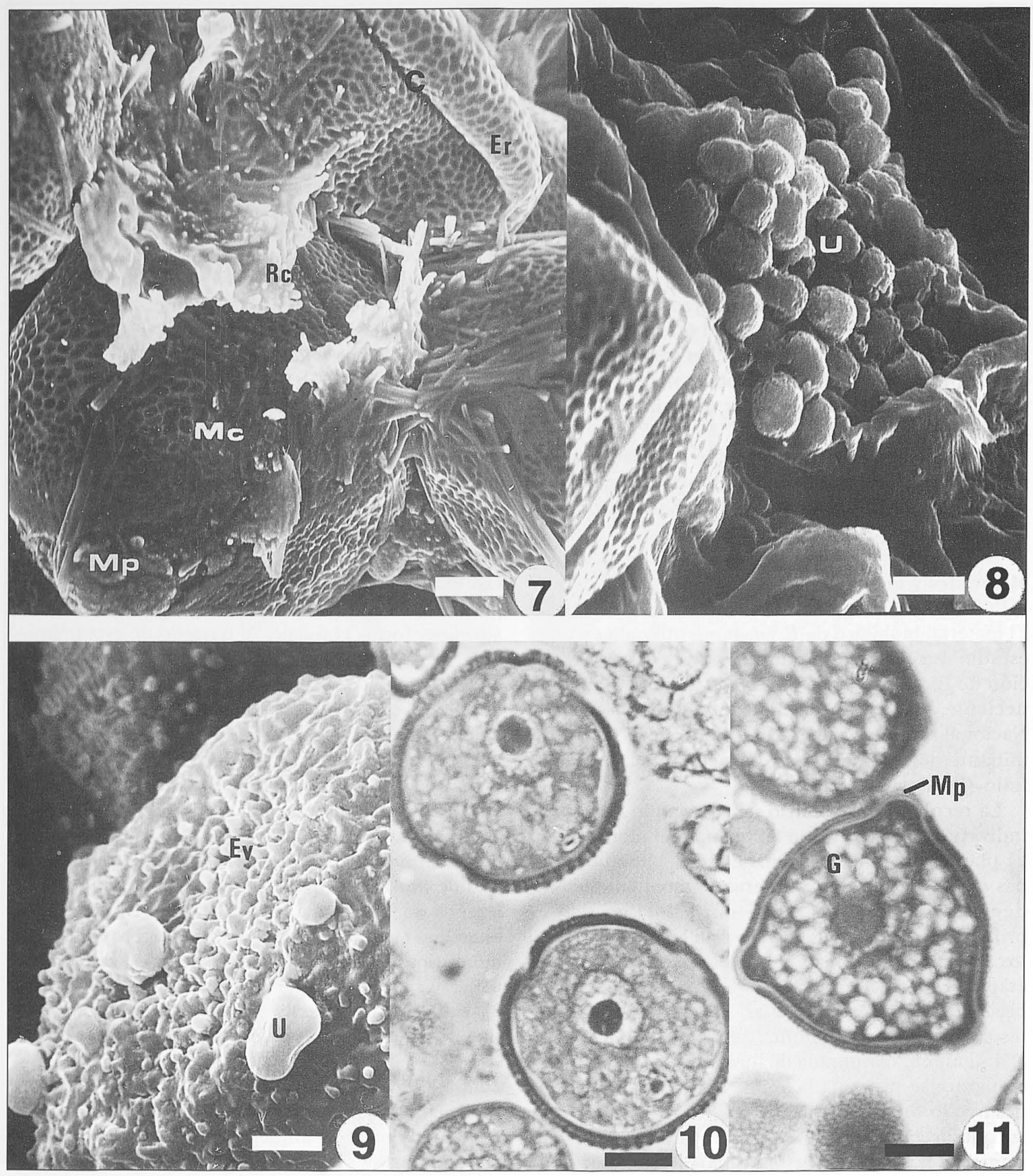

Figuras 7-11. Figura 7. Microsporas al final de la etapa de tétrada del morfo pin. Se observan los restos de calosa (Rc) y exina reticulada (Er), escala $=5 \mu \mathrm{m}$. Figura 8. Cuerpos de Ubisch (U) en células rotas del tapete, escala = $4.5 \mu \mathrm{m}$. Figura 9. Grano de polen del morfo thrum con cuerpos de Ubisch (U) sobre la exina verrugada (Ev), escala $=2.8 \mu \mathrm{m}$. Figura 10. Granos de polen bicelulares, escala $=6.2 \mu \mathrm{m}$. Figura 11. Grano de polen tricolporado con granos de almidón $(\mathrm{G})$ en su interior, escala $=8.8 \mu \mathrm{m}$. $(\mathrm{C}$, colpo; Er, exina reticulada, Ev, exina verrugada; $\mathrm{G}$, grano de almidón; Mc, microspora; Mp, membrana del poro; Rc, restos de calosa; U, cuerpos de Ubisch). 


\section{Microsporogénesis}

Las células madres de las microsporas se preparan para la meiosis depositando calosa a su alrededor (figura 5). El resultado es una tétrada de microsporas del tipo tetrahédrico o algunas veces isobilateral. Cada tétrada se encuentra rodeada por una pared de calosa y cuando ésta se degrada, se observan las microsporas con su pared de exina (figura 7). Las células tapetales se rompen para vertir su contenido al lóculo. Se observan gran cantidad de cuerpos de Ubisch (orbículos), primero en el interior de las células rotas del tapete (figura 8) y posteriormente sobre la pared de los granos de polen jóvenes (figura 9).

\section{Microgametogénesis}

Una vez que se separan las microsporas de las tétradas, se presenta la primera división mitótica y se tiene como resultado un grano de polen binucleado, que es la condición en la que se dispersa (figura 10). Es un grano de polen tricolporado y en su interior hay gran cantidad de granos de almidón (figura 11). La ornamentación de la exina varía entre los morfos, el polen del morfo thrum tiene una exina con escultura verrugada (figura 12), mientras que en el morfo pin la ornamentación es reticulada (figura 13). Esta ornamentación se observa desde que las microsporas salen de la tétrada (figuras 7, 9). No se observaron diferencias significativas con respecto al tamaño de los granos de polen entre los dos morfos

(pin $\mathrm{X}=35.85 \pm 2.4$; thrum $\mathrm{X}=35.7 \pm 1.5$.

Valor de $t=0.178, P=0.178$; $\mathrm{gl}=38$ ).

\section{Desarrollo del gineceo}

En la mayoría de los botones florales bajo estudio se desarrollaron tres carpelos (figura 14), sin embargo, menos de un $5 \%$ de los mismos presentaron cuatro carpelos (figura 15). El ovario es trilocular, tricarpelar y cada carpelo tiene un estilo que termina en un estigma globoso y papilado. Generalmente sólo uno de los carpelos es fértil y forma un óvulo (figura 16). El ovario en su etapa madura presenta un lóculo, porque sólo uno de los tres carpelos que lo forman es fértil. Los otros dos carpelos no desarrollan óvulos y los lóculos se obliteran. En muy pocos casos se observaron dos óvulos en el carpelo fértil.

\section{Desarrollo del óvulo}

Cuando el primordio ovular inicia su desarrollo, el tejido nucelar crece en dirección a la base del estilo, posteriormente gira y crece hacia la base del ovario, por último adopta su posición final girando nuevamente hasta quedar el micrópilo del óvulo frente a la base de los estilos. La célula arquesporial en posición hipodérmica se divide formando dos células: una parietal localizada por abajo de la epidermis y la célula madre de la megaspora . En esta etapa los tegumentos inician su desarrollo (figura 17). Cuando el óvulo adopta su posición final se distinguen claramente los dos tegumentos (figura 18).

La célula parietal se divide tanto anticlinal como periclinalmente varias veces, lo cual trae como consecuencia que la célula madre de la megaspora tenga una posición profunda en la nucela (4-5 estratos), alejada de su posición subhipodérmica original. El óvulo en una flor en antesis es crasinucelado, anátropo y bitégmico, sésil y de placentación axial, aunque parezca parietal debido a la desaparición de los otros dos lóculos, que al colapsarse se confunden con la pared del ovario, dejando como huella únicamente los dos haces vasculares. El óvulo abarca casi todo el lóculo. El micrópilo, formado por el tegumento interno, se orienta en dirección a la inserción de los estilos. La nucela es muy abundante hacia la zona calazal, estando ausente en la zona micropilar, donde se localiza el saco embrionario. Se desarrolla un pequeño obturador del tegumento externo, cerca de la inserción del óvulo a la pared del ovario (figura 18). No fue posible observar las etapas de la megasporogénesis.

\section{Megagametogénesis}

El saco embrionario maduro consta de siete células. Las tres antípodas son efímeras. La célula central binucleada tiene forma de reloj de arena y los núcleos se observan desplazados hacia la región que ocupan las dos sinérgidas y la ovocélula. El saco embrionario a la madurez ocupa una porción muy reducida del óvulo.

\section{Desarrollo de la semilla}

La primera división del cigoto (transversal) se lleva a cabo un día después de la fecundación. Al cuarto día se observa un embrión globular, al noveno un acorazonado y al décimo día se inicia el desarrollo de un embrión con eje cilíndrico (figura 19). El embrión cotiledonario aparece a los trece días postantesis, es recto, presenta un eje hipocótilo-radícula y dos largos cotiledones foliosos que contienen proteínas y almidón (figura 21).

El desarrollo del endospermo es nuclear y se inicia antes de la primera división del cigoto. Los núcleos libres se distribuyen en la periferia del saco embrionario, alrededor de una vacuola central, ocupando el espacio que va dejando al degradarse la nucela. El endospermo inicia su celularización hacia la región micropilar (figura 19) y el almidón contenido en sus células se va consumiendo durante el desarrollo del embrión. 

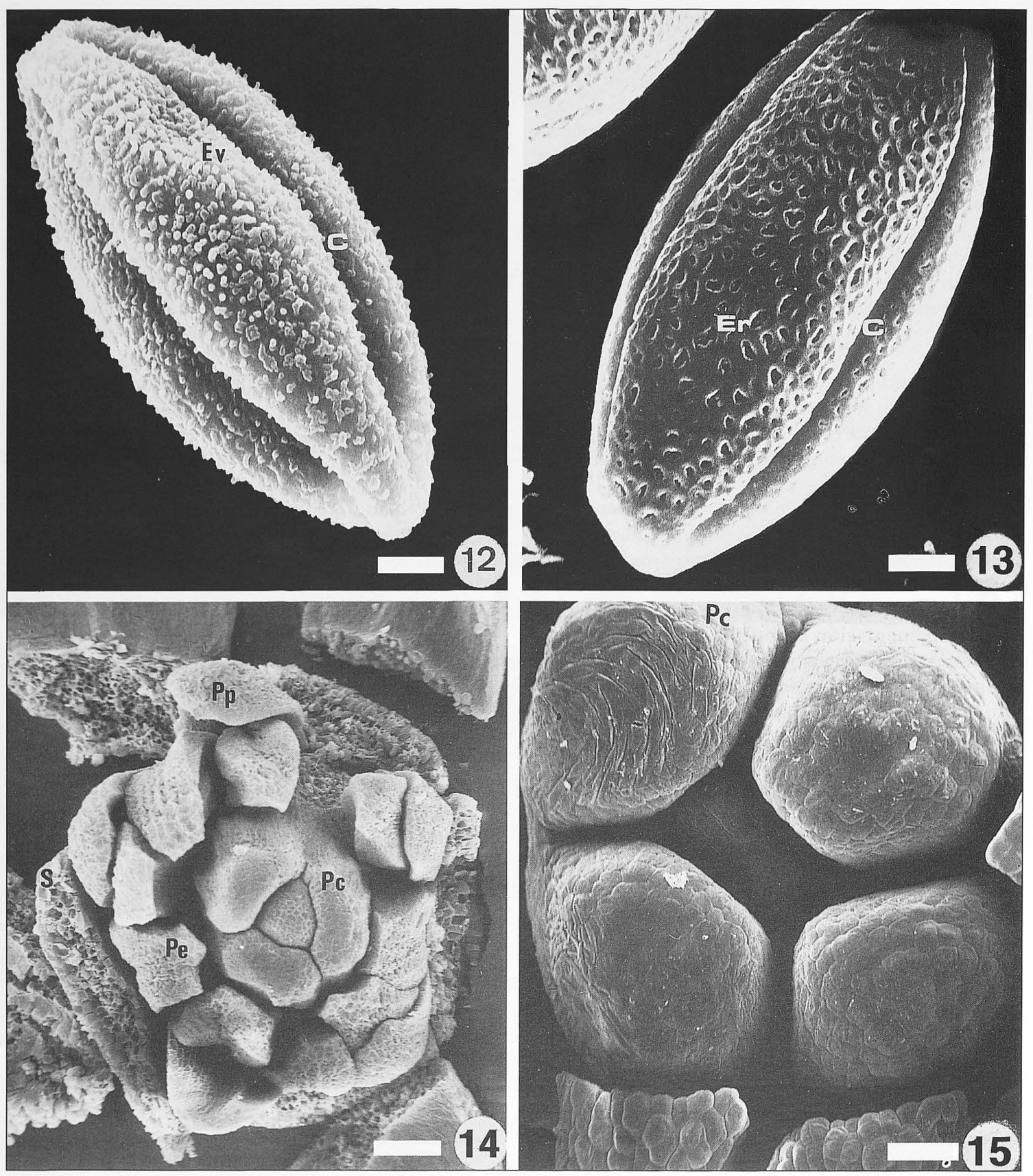

Figuras 12-15. Figura 12. Grano de polen del morfo thrum, exina verrugada (Ev), escala $=5 \mu \mathrm{m}$. Figura 13. Grano de polen del morfo pin, exina reticulada (Er), escala $=4.5 \mu \mathrm{m}$. Figura 14. Botón floral mostrando los primordios de anteras $(\mathrm{Pe})$ y tres primordios carpelares $(\mathrm{Pc})$. Los sépalos $(\mathrm{S})$ fueron removidos, escala $=50 \mu \mathrm{m}$. Figura 15 . Gineceo en desarrollo con cuatro primordios carpelares $(\mathrm{Pc})$, un evento raro, escala $=22.7 \mu \mathrm{m}$. (C, colpo; Er, exina reticulada; Ev, exina verrugada; Pc, primordio carpelar; Pe, primordio de estambre; Pp, primordio de pétalo; S, sépalo). 
La cubierta de la semilla joven está formada por testa y tegmen. Las células de la exotesta se alargan en sentido del eje mayor de la semilla y en ella se encuentran grandes cantidades de taninos. La mesotesta, formada por 5-6 estratos parenquimáticos, o por más en la zona de la rafe, contiene dos haces vasculares que llegan hasta la cálaza, ambos rodeados por células taniníferas. La endotesta es uniestratificada y de células parenquimáticas (figura 20).

El tegmen también tiene tres capas. El exotegmen uniestratificado tiene células parenquimáticas alargadas paralelamente al eje mayor de la semilla, que posteriormente engrosan sus paredes con engrosamientos reticulares y mueren a la madurez. En las zonas de unión entre estas células se forman depresiones hacia el mesotegmen, el cual está formado por células parenquimáticas de gran tamaño y enormes espacios intercelulares (figura 20). El mesotegmen se va consumiendo durante el desarrollo de la semilla (figuras 19 y 21). El endotegmen uniestratificado constituye un endotelio o tapete tegumentario, que está en contacto directo con la nucela (figura 20) y con el saco embrionario en la zona micropilar (figura 18); al desaparecer la nucela, hace contacto con el endospermo. En etapas tempranas del desarrollo el endotelio presenta taninos y durante el desarrollo del embrión éstos desaparecen (figura 19). La unidad de dispersión es el fruto (drupa) de color rojo brillante, que generalmente contiene una sola semilla (figura 21), aunque en casos excepcionales pueden ser dos.

\section{Discusión}

La embriología observada para E. havanense coincide en lo general con lo reportado para el género en lo que se refiere a la estructura y desarrollo de la antera, gametofito masculino, óvulo, organización del saco embrionario, embriogénesis y semilla (Narayana, 1960, 1964, 1970; Boesewinkel y Geenen, 1980). Sin embargo, algunos hallazgos presentados en este trabajo se apartan de lo ya descrito. Davis (1966) y Cronquist (1981) mencionan que el género Erythroxylum comparte óvulos tanto anátropos como hemianátropos. Sin embargo, en todos los trabajos publicados sobre el género (Narayana, 1960, 1964, 1970; Corner, 1976 pp 128-129, 177-178; Boesewinkel y Geenen, 1980; Berry et al., 1991) los óvulos descritos son anátropos, coincidiendo con nuestras observaciones. Esto sugiere que el único tipo de óvulo que presenta el género Erythroxylum es el anátropo.

Siempre se han consignado tétradas de microsporas tetrahédricas para las especies del género, excepto para E. lanceum que además presenta tétradas en decusada (Rao, 1966, citado en Narayana, 1970). En
E. havanense se observan tetrahédricas e isobilaterales. Para el género se han encontrado granos de polen tricelulares al momento de la dispersión, sin embargo, para E. havanense se observaron sólo bicelulares.

Rao (1965, citado en Boesewinkel y Geenen, 1980) menciona que la presencia de dos haces vasculares en la rafe del óvulo tiene alguna relación con la pérdida de funcionalidad de dos de los lóculos y con la reducción en el número de óvulos. No estamos de acuerdo con esta suposición, puesto que, en las raras ocasiones en las que se llegan a desarrollar dos óvulos en el lóculo fértil, cada uno de ellos posee dos haces vasculares. Consideramos que la presencia de dos haces vasculares es una condición sin relación con la disminución del número de óvulos o la obliteración de los lóculos.

El heteromorfismo del polen es clásico de especies heterostílicas. Las diferencias más frecuentes se encuentran en el número de granos de polen y menos frecuentemente en la forma, color o escultura de la exina (Vuilleumier, 1967; Ganders, 1979b; Lloyd y Webb, 1992). Dulberger (1974) menciona que el heteromorfismo del polen se ha reportado en 50 de 55 géneros heterostílicos examinados. Incluso, el tamaño del polen puede diferir entre los juegos de estambres presentes en una misma flor, como sucede en $E$. coca (Ganders, 1979a). En los granos de polen observados en este estudio no encontramos diferencias en el tamaño ni en la coloración, pero sí en la ornamentación de la exina. Estas observaciones difieren de las reportadas por Palacios-Chávez et al. (1986), quienes estudiaron la misma población localizada en Chamela, Jalisco. Ellos solamente encontraron exinas reticuladas, semejantes a otros informes sobre otras especies del género (Erdtman, 1966). Nuestra descripción se basa en repetidas observaciones de granos de polen de anteras en dehiscencia de los morfos por separado, así como en el desarrollo, observando polen de diversos individuos. Es posible que al hacer el estudio palinológico Palacios-Chávez et al. (1986) no hayan tomado muestras de individuos de ambos morfos y sólo estudiaran al morfo pin que presenta exina reticulada.

A pesar de que la posición taxonómica de la familia Erythroxylaceae es controvertida, cualquiera de las clasificaciones acepta su relación estrecha con la familia Linaceae (Cronquist, 1981). Embriológicamente comparten ciertas características: estructura y desarrollo de la antera, gametofito masculino, óvulo, saco embrionario, endospermo y embrión. Sin embargo, se encuentran separadas porque Erythroxylaceae no presenta un obturador y porque la ornamentación de la exina es uniforme (Narayana, 1970). En el trabajo publicado por Boesewinkel y Geenen (1980), se 


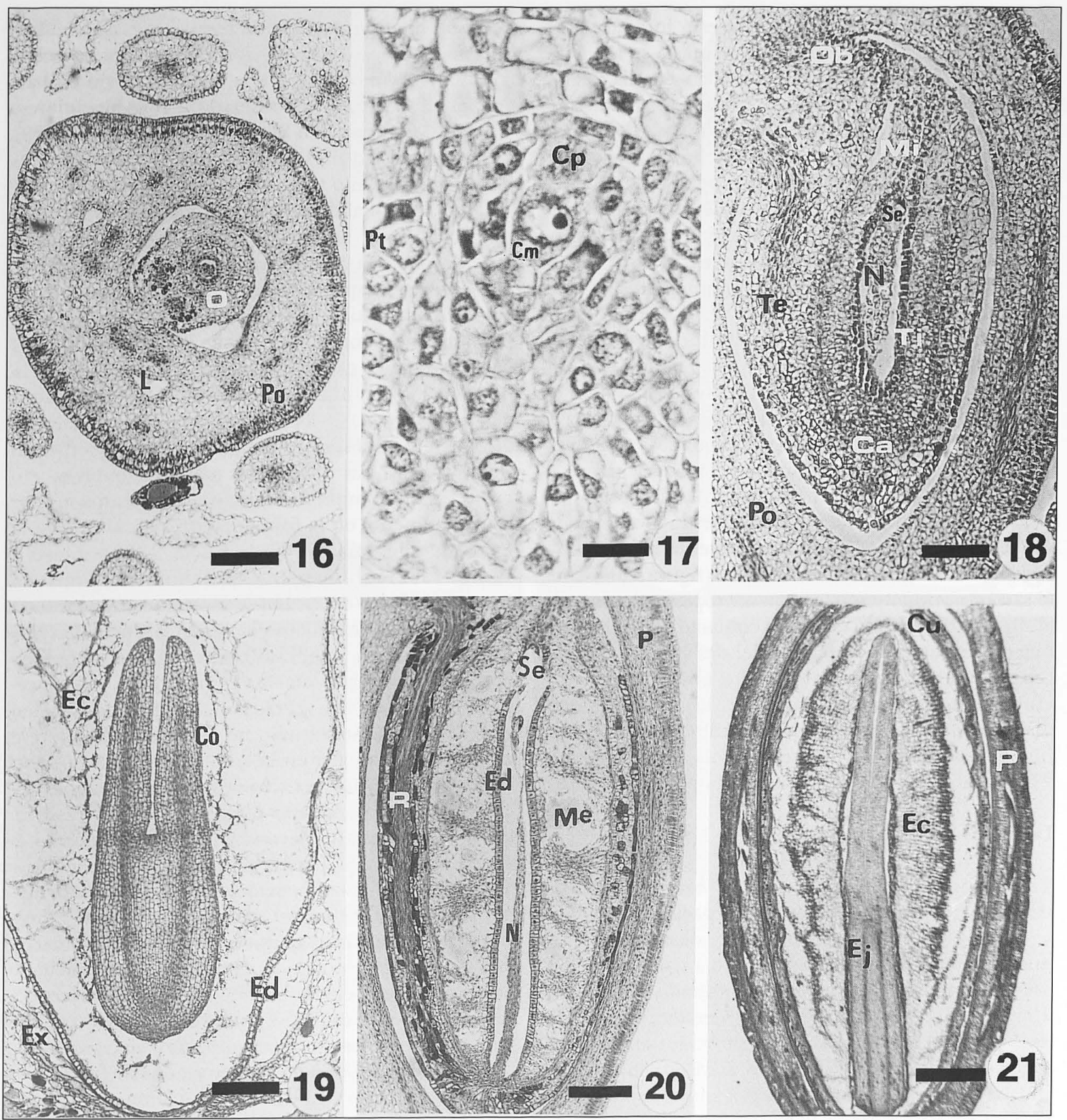

Figuras 16-21. Figura 16. Corte transversal de flor en antesis. Ovario joven trilocular (Po) con un sólo lóculo fértil, escala $=30 \mu \mathrm{m}$. Figura 17. Corte longitudinal de primordio de óvulo. Célula parietal (Cp) y célula madre de la megaspora $(\mathrm{Cm})$, escala $=8.2 \mu \mathrm{m}$. Figura 18. Corte longitudinal de ovario. Ovulo bitégmico, con nucela (N) y saco embrionario, observe el obturador $(\mathrm{Ob})$ escala $=18.9 \mu \mathrm{m}$. Figura 19. Embrión joven con eje cilíndrico. Décimo día postantesis. Observe el endospermo celular y el endotegmen (endotelio, Ed), escala = 13.3 $\mu \mathrm{m}$. Figura 20. Fruto joven, quinto día postantesis, observe la nucela $(\mathrm{N})$ en degradación; la testa y tegmen, escala $=30 \mu \mathrm{m}$. Figura 21. Corte longitudinal de fruto. Observe el embrión con eje cilíndrico (Ej) rodeado por el endospermo celular (Ec). Veinte días postantesis, escala $=450 \mu \mathrm{m}$. (Ca, cálaza; Cm, célula madre de la megaspora; Co, cotiledón; Cp, célula parietal; Cu, cubierta seminal; Ec, endospermo celular; Ed, endotelio; Ej, eje embrionario; Ex, exotegmen; L, lóculo estéril; Me, mesotegmen; Mi, micrópilo; N, nucela; O, óvulo; Ob, obturador; P, pericarpio; Po, pared de ovario; Pt, primordio tegumentario; R, rafe; Se, saco embrionario; Te, tegumento externo; Ti, tegumento interno). 
encuentra un obturador en $E$. coca al igual que lo encontramos aquí para $E$. havanense, además de las diferencias en la ornamentación de la exina del polen. Dado lo anterior, consideramos no válido que estas estructuras se utilicen como argumento para separar ambas familias.

Por último mencionamos que, además de las diferencias en la ornamentación del polen se encontraron otras diferencias entre los morfos pin y thrum que ocasionan una asimetría reproductora entre ambos. Su descripción e interpretación serán tratadas en otro artículo.

\section{Agradecimientos}

Quisieramos agradecer a Felipe Noguera y Ricardo Ayala de la Estación de Biología Chamela (Instituto de Biología, UNAM) por las facilidades brindadas durante el trabajo de campo. Al M. en C. Alejandro Martínez Mena del Laboratorio de Microcine de la Facultad de Ciencias por la toma de microfotografias. A la Biól. Yolanda Hornelas por las fotografías en el microscopio electrónico de barrido. Al Biól. Alfredo Homer Gamboa por la impresiones fotográficas. Este proyecto fue realizado con financiamiento otorgado por el Programa de Apoyo a las Divisiones de Estudios de Posgrado (PADEP) y beca de la Direccción General de Asuntos del Personal Académico (DGAPA).

\section{Literatura citada}

Ávila S.G. 1991. Efectos maternos y paternos sobre la producción de semillas en el desempeño de la progenie del arbusto heterostílico Erythroxylum havanense Jacq. (Erythroxylaceae). Tesis Profesional. Facultad de Ciencias. Universidad Nacional Autónoma de México. México.

Berry P.E., Tobe H, Gómez J.A. 1991. Agamospermy and the loss of distyly in Erythroxylum undulatum (Erythroxylaceae) from Northern Venezuela. American Journal of Botany 78: 595-600.

Boesewinkel F.D., Geenen J. 1980. Development of ovule and seed-coat of Erythroxylum coca Lmk. Acta Botanica Neerlandica 29: 231-241.

Corner E.J.H. 1976. The seeds of dicotyledons. Cambridge University Press, London, $2 \mathrm{v}$.

Cronquist A. 1981. An integrated system of classification of flowering plants. Columbia University Press, New York. 1262 p.

Davis G.L. 1966. Systematic embryology of the angiosperms. John Wiley and Sons, Inc., New York. 528 pp.

Domínguez C.A. 1990. Consecuencias ecológicas y evolutivas del patrón de floración sincrónica y masiva de
Erythroxylum havanense Jacq. (Erythroxylaceae). Tesis Doctoral. Centro de Ecología. Universidad Nacional Autónoma de México. México.

Domínguez C.A., Dirzo R. 1994. Effects of defoliation on Erythroxylum havanense, a tropical proleptic species. Ecology 75: 1896-1902.

Domínguez C.A., Dirzo R. 1995. Rainfall and flowering synchrony in a tropical shrub: variable selection on the flowering time of Erythroxylum havanense. Evolutionary Ecology 9: 204-216.

Dulberger R. 1974. Structural dimorphism of stigmatic papillae in dystylous Linum species. American Journal of Botany 61: 238-243.

Erdtman G. 1943. An introduction to pollen analysis. The Ronald Press Co., New York. 239 pp.

Erdtman G. 1966. Pollen morphology and plant taxonomy. Angiosperms. Hafner Publishing Co., New York. 553 pp.

Ganders F.R. 1979a. Heterostyly in Erythroxylum coca (Erythroxylaceae). Botanical Journal of the Linnean Society 78: 1-20.

Ganders F.R. 1979b. The biology of heterostyly. New Zealand Journal of Botany 17: 607-635.

Gryj R.E.O. 1990. Dispersión de frutos del arbusto Erythroxylum havanense Jacq. en Chamela, Jalisco. Tesis Profesional. Facultad de Ciencias. Universidad Nacional Autónoma de México. México.

Johansen D.A. 1940. Plant microtechnique. McGraw-Hill, New York. 523 pp.

Lloyd D.G., Webb C.J. 1992. The evolution of heterostyly. En Barrett S.C.H. (ed.), Evolution and function of heterostyly. Springer-Verlag, New York, NY. pp 151-178.

Narayana L.L. 1960. Studies in Erythroxylaceae I. Proc. Indian Academic Science 51: 270-275.

Narayana L.L. 1964. Embryology of a few species of Erythroxylum. Current Science 33: 441-442.

Narayana L.L. 1970. Erythroxylaceae. En: Symposium on comparative embryology of angiosperms, Delhi. Bulletin Indian Natural Science Academy 41: 133-135.

Palacios-Chávez R., Arreguín-Sánchez M de la L., QuirozGarcía D.L., Ramos-Zamora D. 1986. Morfología de los granos de polen del género Erythroxylum (Erythroxylaceae) de Chamela, Jalisco. Phytologia 61: 150-157.

Rzedowski J. 1978. La vegetación de México. Limusa, México.

Standley P.C. 1923. Trees and shrubs of Mexico. Contributions for the United States National Herbarium. 23: 517-848.

Valley P. 1976. JB-4 embedding kit. Polysciences Inc. Warrington. Printed in U.S.A. 1-3 pp.

Vuilleumier B.S. 1967. The origin and evolutionary development of heterostyly in the angiosperms. Evolution 21: 210-226. 